\title{
Stress and displacement pattern evaluation using two different palatal expanders in unilateral cleft lip and palate: a three- dimensional finite element analysis
}

\author{
Anoop Mathew ${ }^{1}$, K. S. Nagachandran ${ }^{2 *}$ and Devaki Vijayalakshmi ${ }^{2}$
}

\begin{abstract}
Background: In this finite element (FE) study, the stress distribution and displacement pattern was evaluated in the mid-palatal area and around circum-maxillary sutures exerted by bone-borne palatal expander (BBPE) in comparison with conventional HYRAX rapid palatal expander in unilateral cleft lip and palate.

Methods: Computed tomography scan images of a patient with unilateral cleft palate was used to create a FE model of the maxillary bone along with circum-maxillary sutures. A three-dimensional model of the conventional HYRAX (Hygienic Rapid Expander) expander and custom-made BBPE was created by laser scanning and programmed into the FE model.

Results: With the BBPE, the maximum stress was observed at the implant insertion site, whereas with the conventional HYRAX expander, it was at the dentition level. Among the circum-maxillary sutures, the zygomaticomaxillary suture experienced maximum stress followed by the zygomaticotemporal and nasomaxillary sutures. Displacement in the $X$-axis (transverse) was highest on the cleft side, and in the $Y$-axis (antero-posterior), it was highest in the posterior region in the BBPE.

Conclusions: The total displacement was observed maximum in the mid-palatal cleft area in the BBPE, and it produced true skeletal expansion at the alveolar level without any dental tipping when compared with the conventional HYRAX expander.
\end{abstract}

Keywords: Finite element method, Rapid palatal expansion, Microimplant, Cleft lip and palate

\section{Background}

Cleft lip and palate (CLP) is the most common craniofacial malformation characterized by underdeveloped maxilla both in transverse and sagittal dimension which can be corrected by surgical repair of the cleft followed by orthodontic treatment [1].

So far, the slow and rapid maxillary expansion appliances [2-10] that were tooth supported achieved expansion which were $50 \%$ dental in nature $[11,12]$.

\footnotetext{
* Correspondence: orthoksn@yahoo.co.in

${ }^{2}$ Department of Orthodontics and Dentofacial Orthopedics, Meenakshi

Ammal Dental College \& Hospital, Meenakshi University (MAHER), Alapakkam

Main Road, Maduravoyal, Chennai, Tamilnadu 600095, India

Full list of author information is available at the end of the article
}

In recent years, bone-anchored rapid palatal expanders were developed with the advantage of directly anchoring the appliance to the palatal bone and many of them could achieve sufficient skeletal expansion without producing dental ill effects [13-19].

Several finite element (FE) analysis studies have been performed to assess the various biomechanical effects of rapid palatal expansion (RPE) in non-cleft patients [20-23]. Also, few studies have been reported analysing the stress pattern caused by conventional RPE appliances in CLP patients $[24,25]$. Despite the varying conclusions that have been made in the literature regarding the differences between bone-anchored and tooth-borne rapid maxillary expansion, till date, no study has investigated the biomechanical effects 
of implant-supported RPE in cleft palate patients versus tooth-borne RPE.

Therefore, the purpose of this study was to evaluate the stress distribution and displacement pattern in the mid-palatal suture area and around circum-maxillary sutures using bone-borne palatal expander in a patient with unilateral cleft lip and palate in comparison with conventional HYRAX rapid maxillary expansion appliance using finite element analysis.

\section{Methods}

\section{FEM model preparation}

A computed tomographic scan of a 12-year-old patient with unilateral cleft lip and palate was obtained as a requisite for pre-treatment record which was approved by the institutional ethical committee. Then, the CT scan of the maxilla along with the teeth and circum-maxillary sutures was converted into a 3D model for finite element (FE) modelling.

The conventional HYRAX expansion screw (Leone, Italy) was laser scanned using a white light 3D scanner (Model: SmartScan 3D 2275, Breuckmann GmbH), and a 3D model was created (Fig. 1a). This expansion screw was activated to bring about 0.25 - $\mathrm{mm}$ widening per turn, and twice a day activation protocol was followed.

Then, a custom-fabricated bone-borne palatal expander (BBPE) was constructed which consisted of a modified HYRAX expander (Leone, Italy) which enables microimplant placement and was laser scanned to create a 3D model (Fig. 1b).

In this study, C-implant (C-implant Co., Seoul, Korea) with a $1.8-\mathrm{mm}$ diameter and $8.5-\mathrm{mm}$ length was used and four implants were positioned in the FE model on the palatal slope: two between the canines and first pre-molars and two between the second pre-molars and first molars on both the left and right sides. The placement site for the microimplant was chosen based on the extent of the cleft and availability of the bone verified with the CT scan data within the biological limits without affecting the principles of design of the palatal expansion screw.

\section{Material properties}

The material properties were assigned to the various structures such as the teeth, cancellous and compact bone and stainless steel in the FE model which are given in Table 1 and are in confirmation with the data available from previous studies [20-22, 26, 27].

\section{Boundary conditions and solution}

The process of meshing was carried out using pre-processor software Altair HyperMesh (Version 7.0), and specific boundary conditions were applied. Finally, the 3D FE model created consisted of 255,140 tetrahedral elements and 255,270 nodes.

The FE model was imported into ANSYS software (version 14.5), and various considerations are established. The laser-scanned conventional HYRAX expander and bone-borne palatal expander was attached onto the FE model. About 5-N force was applied to the model simulating the clinical situation, and analysis was performed which has been reported previously [24].

Analysis was done using a Newton-Raphson method of solving which efficiently handles non-linear problems accurately.

\section{Results}

Stress distribution in the mid-palatal area and circummaxillary sutures in cleft palate

In this study, with the bone-borne palatal expander, a greater amount of stress $(4.320 \mathrm{MPa})$ was seen at the implant insertion site (Fig. 3). Also, the stress experienced in the primary palate cleft area assessed in the canine region was $0.8507 \mathrm{MPa}$, and the left and right sides of the cleft in the pre-maxillary region were 0.31694 and $0.1096 \mathrm{MPa}$, respectively. This is greater than that of the conventional HYRAX expander (Fig. 2). The comparison of stress created by the two appliances is shown in Table 2.

Similarly, in the secondary palate, the stress values in the pre-molar and first molar area were greater than that of the HYRAX expander (Fig. 3).

In the circum-maxillary sutures, the highest stress was observed in the zygomaticomaxillary suture area $(0.6079 \mathrm{MPa})$ which was followed by the zygomaticotemporal $(0.0855 \mathrm{MPa})$ and nasomaxillary $(0.2343 \mathrm{MPa})$ sutures in the BBPE when compared to the HYRAX expander (Fig. 4).

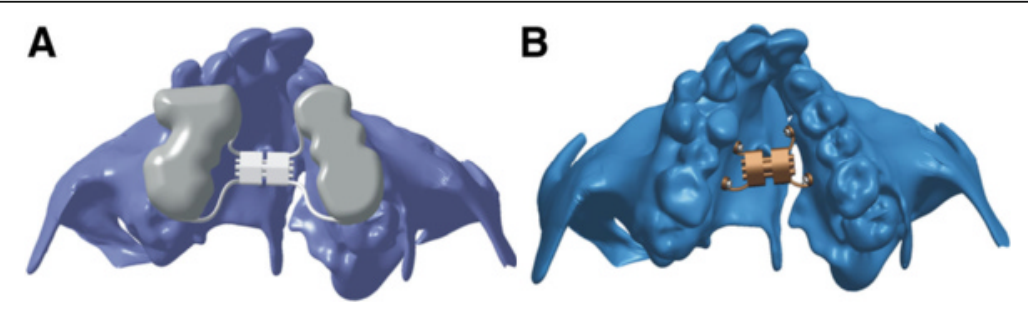

Fig. 1 Three-dimensional model of a conventional HYRAX expander and $\mathbf{b}$ bone-borne palatal expander 
Table 1 Material properties and elements used in the present study

\begin{tabular}{lllll}
\hline S. no & Structures & $\begin{array}{l}\text { Elements } \\
\text { and nodes }\end{array}$ & $\begin{array}{l}\text { Young's modulus } \\
(\mathrm{MPa})\end{array}$ & $\begin{array}{l}\text { Poisson's } \\
\text { ratio }\end{array}$ \\
\hline 1 & Cortical bone & Tetrahedral & 13,700 & 0.30 \\
2 & Cancellous bone & Tetrahedral & 7900 & 0.30 \\
3 & Sutures & Tetrahedral & 10 & 0.49 \\
4 & Teeth & Tetrahedral & 20,000 & 0.30 \\
\hline
\end{tabular}

\section{Displacement pattern for the BBPE in comparison with} the conventional HYRAX palatal expander

In the $X$-axis (transverse), maximum displacement was observed on the cleft side for both expanders (Fig. 5). In the BBPE, the displacement pattern was evenly distributed from the palatal slope to the dentition, whereas in the conventional expander, the displacement was concentrated maximum at the dentition level.

In the $Y$-axis (antero-posterior), the maximum amount of displacement was observed in the posterior area, which was evenly extending anteriorly along the mid-palatal suture area in the BBPE, whereas in the conventional expander, the maximum displacement was seen in the cleft side concentrated more at the dentition level (Fig. 6).
In the $Z$-axis (vertical), the displacement was highest superiorly on both the cleft and non-cleft sides in the BBPE when compared to the conventional HYRAX expander where the displacement was maximum superiorly but more on the cleft side (Fig. 7).

Overall in all the axes, the maximum amount of displacement was seen along the mid-palatal suture area in the canine, pre-molar and molar regions with the BBPE when compared to the conventional HYRAX expander which is given in Tables 3 and 4 .

\section{Discussion}

RPE has been advocated for correcting maxillary transverse deficiency in cleft lip and palate followed by bone grafting [11]. Owing to the difficulty to achieve orthopaedic expansion with RPE alone, it is often combined with a surgically assisted procedure [12]. Recently, microimplant-anchored skeletal expansion can be a viable option which eliminates the need for surgical procedure [14-17].

Vyas et al. reported that the use of microimplantassisted palatal distraction as an adjunct to SARPE provided adequate stable skeletal expansion [28]. Even though clinically they could achieve the skeletal expansion, the

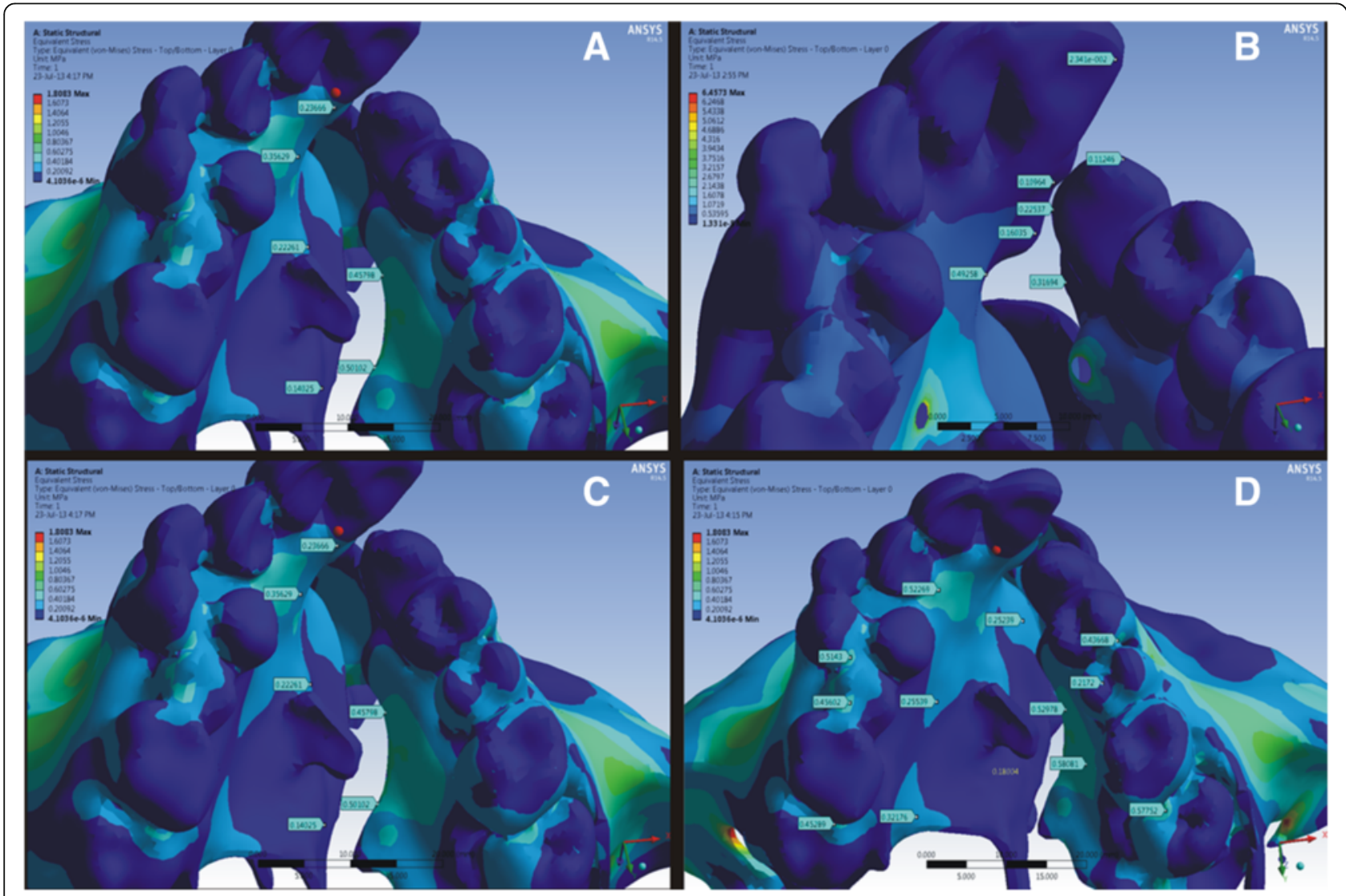

Fig. 2 Von Mises stress distribution for the bone-borne HYRAX expander around the a mid-palatal suture area, b pre-maxillary region, $\mathbf{c}$ left palatal slope and $\mathbf{d}$ right palatal slope 
Table 2 Stress distribution (MPa) around the sutures and the cleft area

\begin{tabular}{|c|c|c|c|c|c|}
\hline S. no & Sutures & Areas & & Bone-borne palatal expander & Conventional HYRAX \\
\hline \multirow[t]{2}{*}{1} & \multirow[t]{2}{*}{ Pre-maxilla cleft area } & Non-cleft side & & 0.1096 & 0.2499 \\
\hline & & Cleft side & & 0.31694 & 0.12464 \\
\hline \multirow[t]{6}{*}{2} & \multirow[t]{6}{*}{ Mid-palatal cleft area } & \multirow[t]{2}{*}{ Molars } & Non-cleft side & 0.6899 & 0.1835 \\
\hline & & & Cleft side & 0.6824 & 0.4234 \\
\hline & & \multirow[t]{2}{*}{ Pre-molars } & Non-cleft side & 0.6204 & 0.2839 \\
\hline & & & Cleft side & 0.6144 & 0.1043 \\
\hline & & \multirow[t]{2}{*}{ Canine } & Non-cleft side & 0.8507 & 0.4001 \\
\hline & & & Cleft side & 0.7868 & 0.0779 \\
\hline \multirow[t]{2}{*}{3} & \multirow[t]{2}{*}{ Zygomaticomaxillary suture } & \multicolumn{2}{|l|}{ Non-cleft side } & 0.56649 & 0.34412 \\
\hline & & \multicolumn{2}{|l|}{ Cleft side } & 0.6079 & 0.6046 \\
\hline \multirow[t]{2}{*}{4} & \multirow[t]{2}{*}{ Zygomaticotemporal suture } & \multicolumn{2}{|l|}{ Non-cleft side } & 0.7419 & 0.6104 \\
\hline & & \multicolumn{2}{|l|}{ Cleft side } & 0.0855 & 0.10168 \\
\hline \multirow[t]{2}{*}{5} & \multirow[t]{2}{*}{ Nasomaxillary suture } & \multicolumn{2}{|l|}{ Non-cleft side } & 0.69559 & 0.50771 \\
\hline & & \multicolumn{2}{|l|}{ Cleft side } & 0.2343 & 0.33451 \\
\hline
\end{tabular}

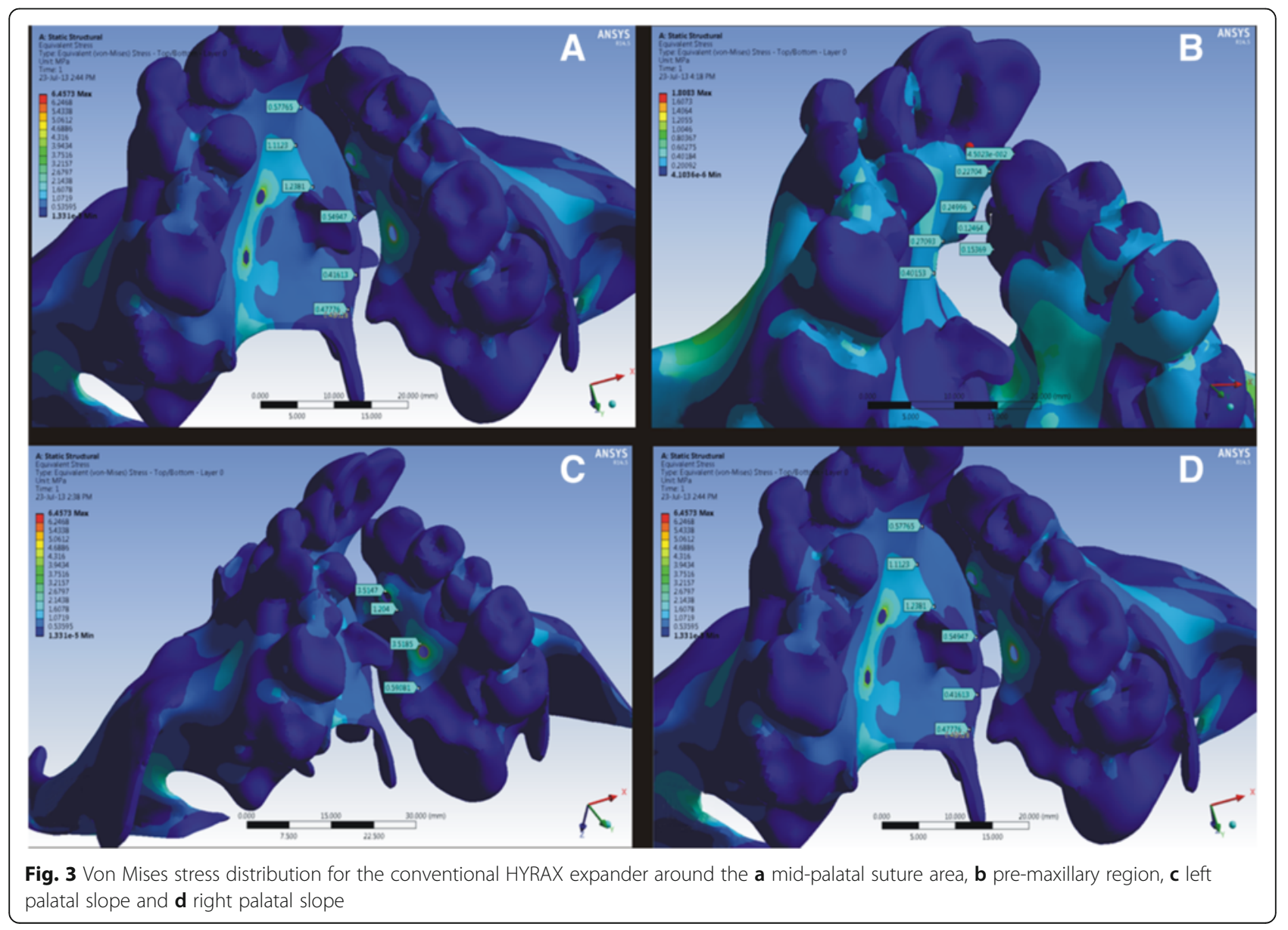



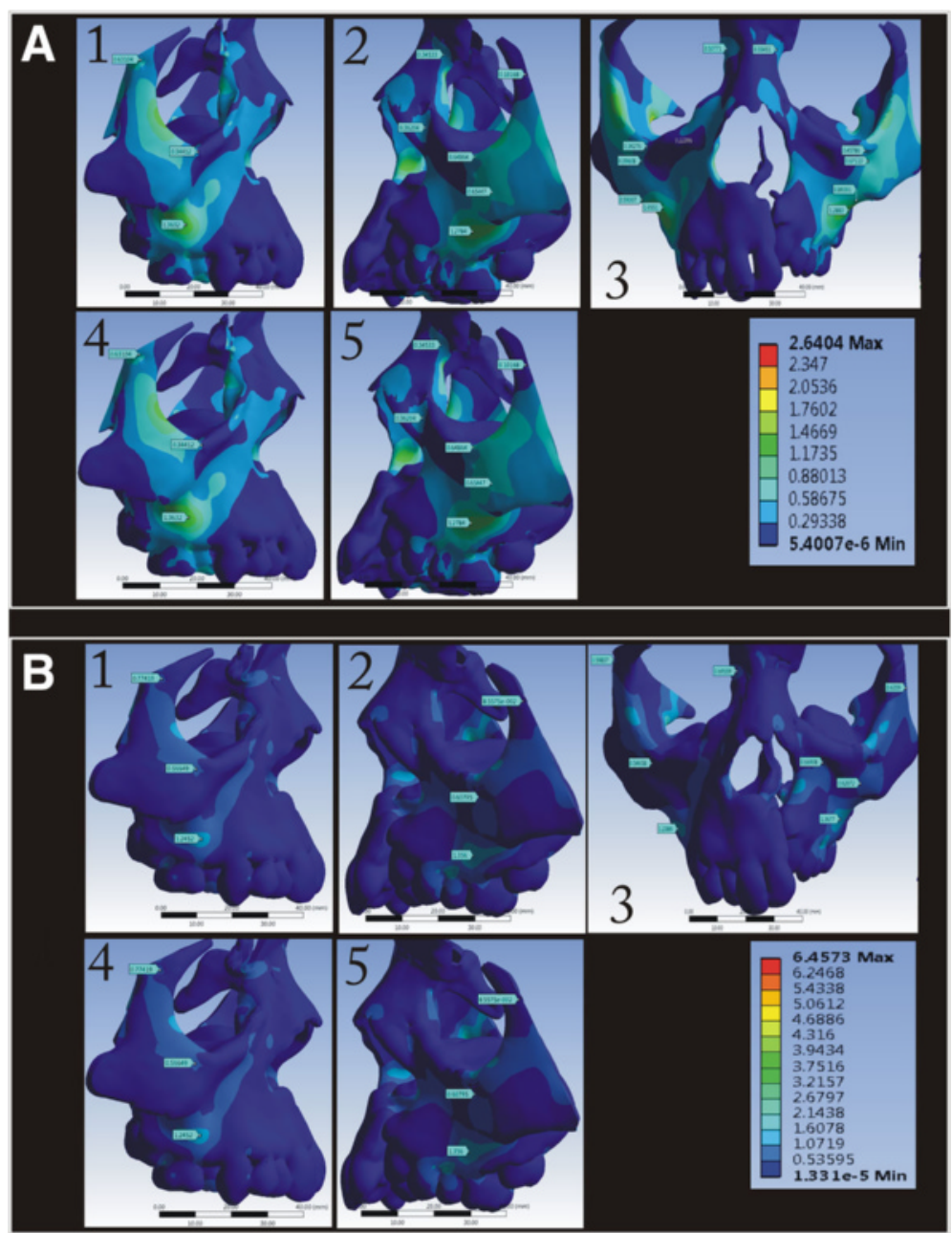

Fig. 4 Von Mises stress fields around the circum-maxillary sutures in the a conventional HYRAX expander and b bone-borne HYRAX expander (a1, b1, zygomaticomaxillary suture non-cleft side; a2, b2, zygomaticomaxillary suture cleft side; a3, b3, nasomaxillary suture; a4, b4, zygomaticotemporal suture non-cleft side; and a5, b5, zygomaticotemporal suture cleft side)

complex loading pattern and the biomechanical effects of this bone-borne palatal expander on the maxillary bone and the circum-maxillary sutures have not been evaluated. Hence, in the present study, we have used the bone-borne palatal expander and evaluated the stress distribution and displacement pattern using a finite element method.

The implants were placed on the palatal slopes to achieve efficient palatal expansion. Our results showed that with the BBPE, the greatest stress was seen at the implant insertion site which was gradually distributed along the palatal slopes on the cleft and non-cleft sides which is similar to the study reported by Lee et al. [29].

However, the stress distribution in the mid-palatal suture area was not clearly interpreted since there is absence of fusion of two palatal shelves in cleft palate. For this reason, we assessed the stress around the midpalatal suture area in the pre-maxilla, canine, pre-molar and molar regions. With the BBPE, the greatest stress was observed around the pre-maxillary region as well as at the secondary palatal area when compared to the conventional HYRAX expander.

Holberg et al. in their finite element study has reported that RPE can produce up to $120 \mathrm{~N}$ of force and suggested that slow expanders with forces of about $5 \mathrm{~N}$ will suffice to bring about the necessary skeletal expansion in cleft patients $[24,30]$. However, in the present study, we applied about $5 \mathrm{~N}$ of force in the $\mathrm{FE}$ model and evaluated the stress distribution around the cleft palate area and the circum-maxillary sutures.

Lee et al. reported that the maximum amount of orthodontic force that can be tolerated by the microimplant is about $400 \mathrm{~g}$ and with implants that are $1.8 \mathrm{~mm}$ in diameter, $400 \mathrm{~g}$ of orthodontic loading produces $30 \mathrm{MPa}$ of force [31]. Furthermore, recent studies have reported that the mini-screws with an optimal 9-mm length had the ability to withstand about $2 \mathrm{~N}$ of force 

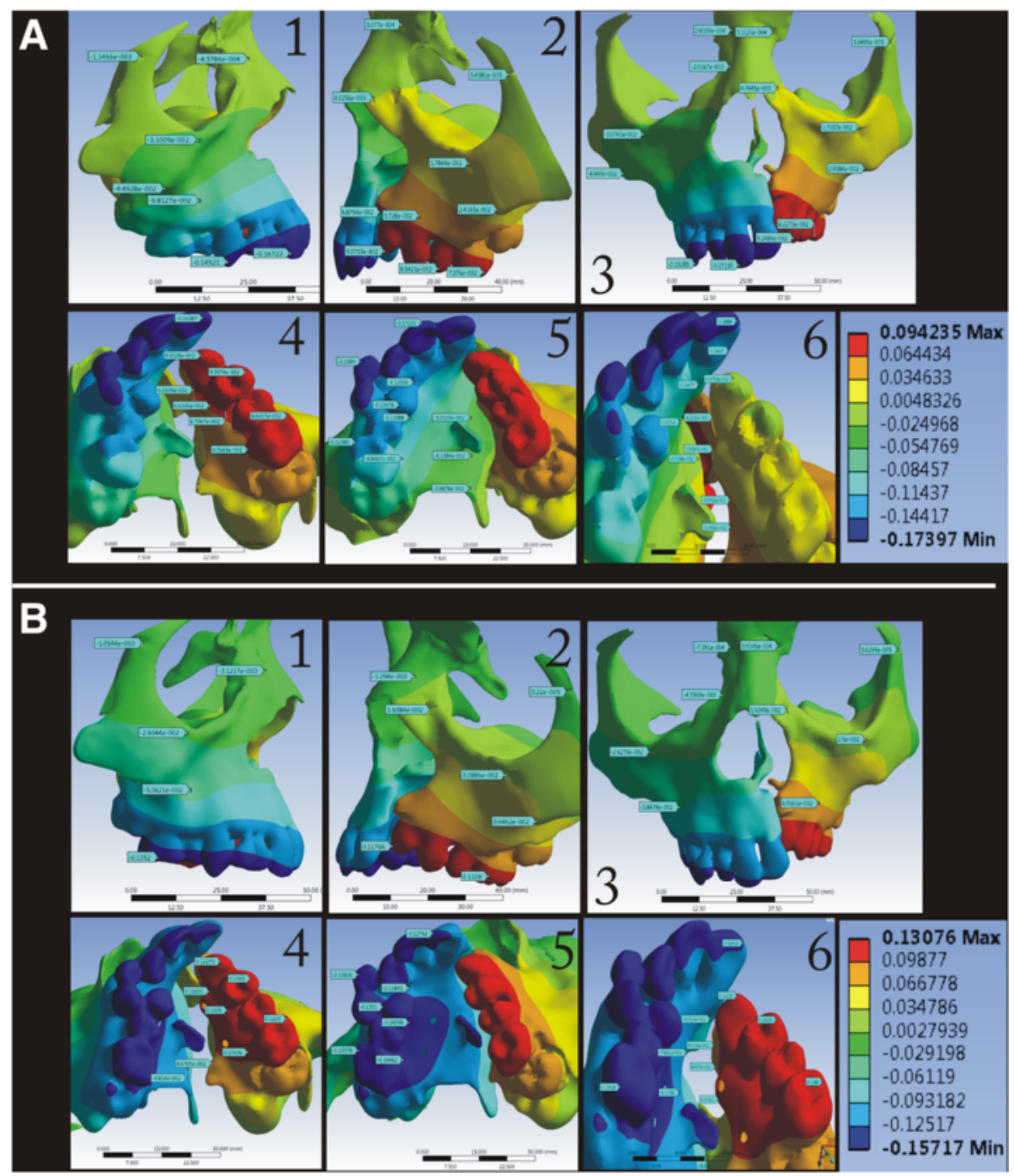

Fig. 5 Displacement pattern in the $X$-axis for the a conventional HYRAX expander and $\mathbf{b}$ bone-borne HYRAX expander (a1, b1, non-cleft side; a2 b2, cleft side; a3, b3, frontal view; a4, b4, left palatal slope; a5, b5, right palatal slope; and a6, b6, mid-palatal area)

without breakage [32, 33]. However, in order to achieve orthopaedic maxillary expansion, it is necessary to apply $5 \mathrm{~N}$ of force which has been already reported by Holberg et al. [24], and hence, we applied $5 \mathrm{~N}$ of force in our study.

Moreover, due to certain limitations, we confined the force level to only $5 \mathrm{~N}$ and future studies might provide further information regarding the stress distribution produced by different force levels with this type of BBPE appliance and can predict ideal force levels and activation protocols.

Furthermore, the unilateral cleft maxilla FE model created by Holberg et al. [24] included about 30,138 tetrahedral elements and 55,064 nodes. In the present study, we have used 255,140 tetrahedral elements and 255,270 nodes to create a refined 3D unilateral cleft maxillary FE model. Studies have reported that the periodontal ligament of the teeth and the viscoelastic property when incorporated in a FE model will greatly influence the outcome of the stress distribution in a traditional tooth-borne rigid palatal expansion appliance $[20,34,35]$. Nonetheless, in the present study, the BBPE used is directly anchored to the bone but not to the teeth.

In the BBPE, transverse displacement was greater at the dentoalveolar region without buccal tipping of the teeth in the contrary conventional expander displaced at the dentition level. Hence, true skeletal expansion can be achieved in cleft palate with the BBPE since the forces are concentrated directly at the alveolar bone level. Nevertheless the bone available, the site of implant placement has to be considered as a pre-requisite, and the appliance design might vary in various cleft palate conditions before using the BBPE.

Among the circum-maxillary sutures, the zygomaticomaxillary suture on the cleft side experienced the highest stress with the BBPE when compared to the 

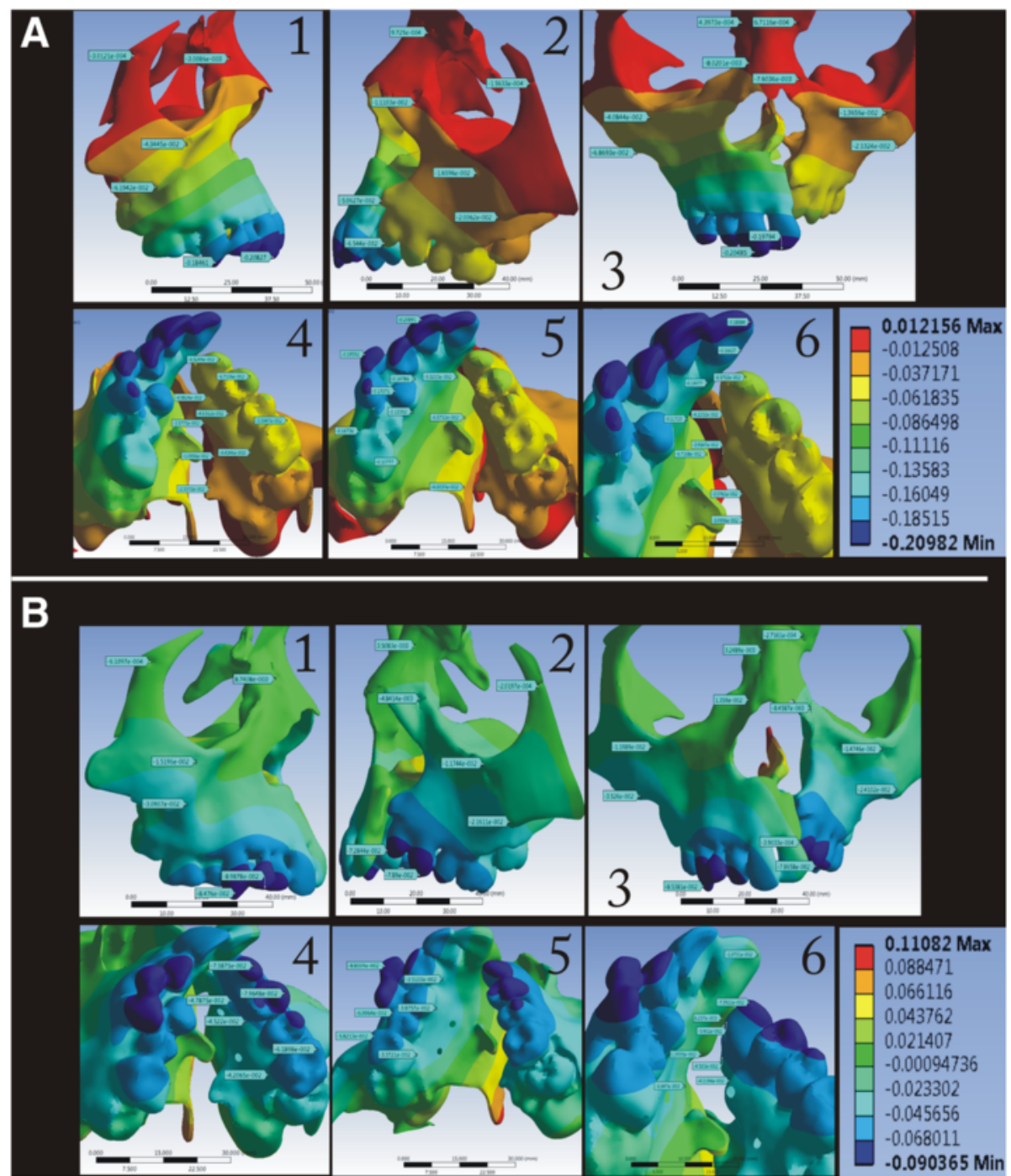

Fig. 6 Displacement pattern in the Y-axis for the a conventional HYRAX expander and $\mathbf{b}$ bone-borne HYRAX expander (a1, b1, non-cleft side; a2, b2, cleft side; a3, b3, frontal view; a4, b4, left palatal slope; a5, b5, right palatal slope; and a6, b6, mid-palatal area)

conventional HYRAX expander than on the non-cleft side. This agrees with the previous study reported by Gautam et al. [36, 37]. Several studies have also shown that the zygomatic buttress offers the primary resistance to different expansive forces in the circum-maxillary area [36-39]. Melsen and Melsen have reported that disarticulation is difficult in adolescents and adults due to heavy inter-digitations between the maxilla, palatine and pterygoid process of the sphenoid bone [40].

Stress at the zygomaticotemporal and nasomaxillary sutures on both the cleft and non-cleft sides in the BBPE was greater than that of the conventional HYRAX expander. However, the amount of stress experienced in these sutures was less than that of at the zygomaticomaxillary suture.

Recently, Ngan et al. had reported that in non-cleft class III individuals, the hybrid HYRAX bone-borne expansion device along with maxillary protraction yielded desirable sagittal skeletal change with minimal dental side effects [41]. Also Lin et al had concluded that in non-cleft individuals bone-borne maxillary expansion produced greater transverse orthopedic effects [42]. In such a case, if alternate expansion and constriction protocol is combined with BBPE, it might provide adequate disarticulation and future studies will define a refined expansion protocol in cleft palate patients.

Like many other finite element studies, this study without exception also has limitation due to the mathematical model as well as premises and assumptions used to generate the FE from a single patient which might not completely resemble the general population with individual variability as well as various clinical situations such as mid-palatal sutural viscoelastic property. 

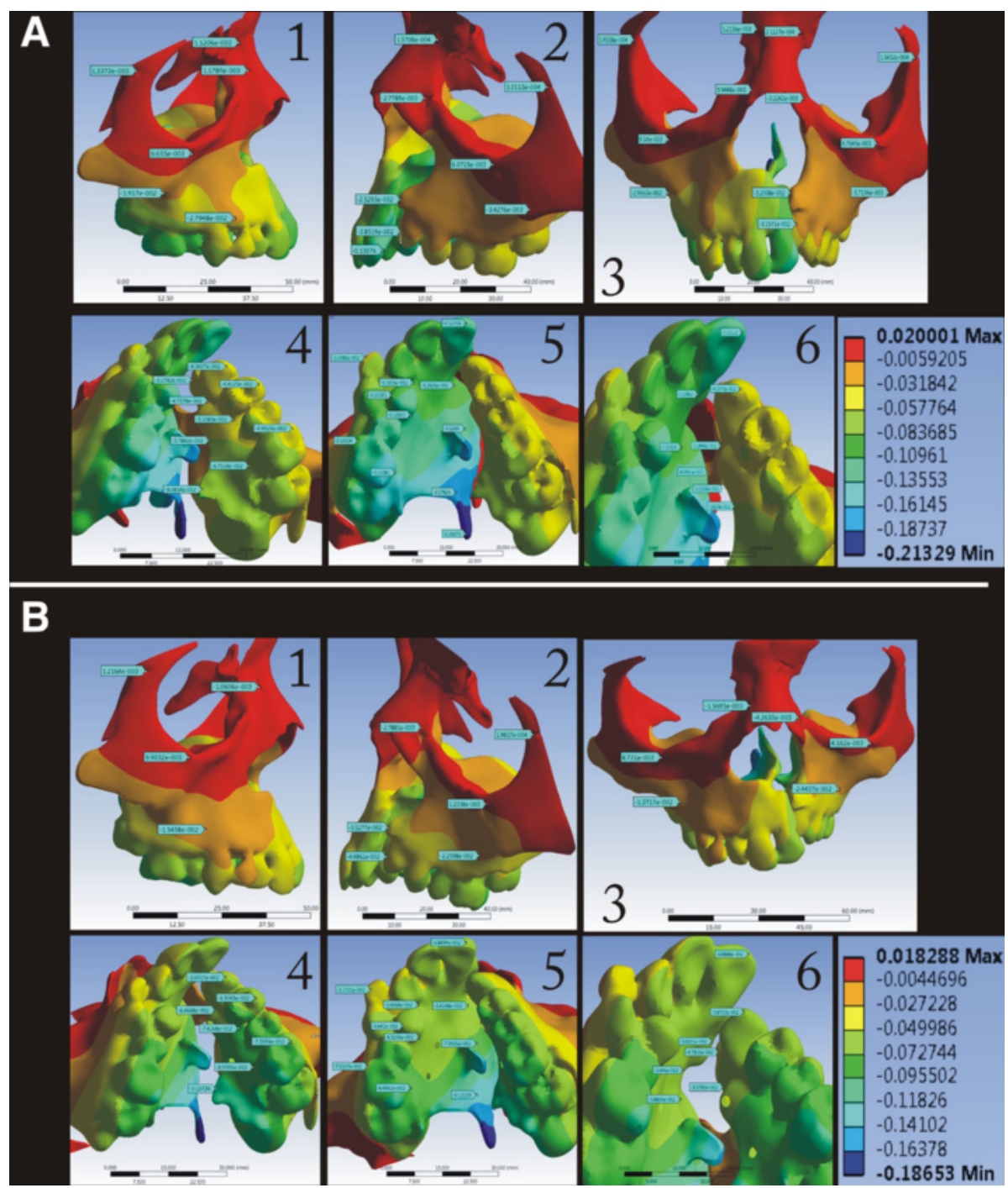

Fig. 7 Displacement pattern in the Z-axis for the a conventional HYRAX expander and $\mathbf{b}$ bone-borne HYRAX expander (a1, b1, non-cleft side; a2 b2, cleft side; a3, b3, frontal view; a4, b4, left palatal slope; a5, b5, right palatal slope; and a6, b6, mid-palatal area)

\section{Conclusions}

- In the mid-palatal suture area, the greatest stress was observed at the implant insertion site on the cleft side along the palatal slopes and was evenly distributed superiorly to the alveolar and basal bone region with the use of the BBPE, whereas in the conventional HYRAX expander, the greatest stress was observed at the dentition level both on the cleft and non-cleft sides.

- Among the circum-maxillary sutures, the zygomaticomaxillary suture experienced the highest stress when using the BBPE which was followed by the zygomaticotemporal and nasomaxillary sutures

Table 3 Displacement $(\mathrm{mm})$ at the alveolar level in all three axes

\begin{tabular}{|c|c|c|c|c|c|c|c|c|c|c|c|c|}
\hline \multirow[t]{3}{*}{ Alveolar level } & \multicolumn{6}{|c|}{ Conventional HYRAX rapid maxillary expander } & \multicolumn{6}{|c|}{ Bone-borne palatal expander } \\
\hline & \multicolumn{3}{|c|}{ Cleft side } & \multicolumn{3}{|c|}{ Non-cleft side } & \multicolumn{3}{|c|}{ Cleft side } & \multicolumn{3}{|c|}{ Non-cleft side } \\
\hline & $X$-axis & Y-axis & Z-axis & $X$-axis & Y-axis & Z-axis & $X$-axis & $Y$-axis & Z-axis & $X$-axis & Y-axis & Z-axis \\
\hline Canine region & 0.06330 & 0.04582 & 0.04773 & 0.01203 & 0.01447 & 0.09143 & 0.11031 & 0.04787 & 0.06464 & 0.01189 & 0.03510 & 0.05406 \\
\hline Pre-molar region & 0.06619 & 0.04656 & 0.05108 & 0.01108 & 0.01339 & 0.01260 & 0.1106 & 0.04522 & 0.07426 & 0.01409 & 0.03875 & 0.06320 \\
\hline Molar region & 0.06764 & 0.04434 & 0.06751 & 0.08868 & 0.01077 & 0.01338 & 0.10636 & 0.04206 & 0.08959 & 0.01444 & 0.03372 & 0.08486 \\
\hline
\end{tabular}


Table 4 Displacement ( $\mathrm{mm}$ ) at the dentition level in all three axes

\begin{tabular}{|c|c|c|c|c|c|c|c|c|c|c|c|c|}
\hline \multirow[t]{3}{*}{ Dentition level } & \multicolumn{6}{|c|}{ Conventional HYRAX rapid maxillary expander } & \multicolumn{6}{|c|}{ Bone-borne palatal expander } \\
\hline & \multicolumn{3}{|c|}{ Cleft side } & \multicolumn{3}{|c|}{ Non-cleft side } & \multicolumn{3}{|c|}{ Cleft side } & \multicolumn{3}{|c|}{ Non-cleft side } \\
\hline & $X$-axis & Y-axis & Z-axis & $X$-axis & Y-axis & Z-axis & $X$-axis & Y-axis & Z-axis & $X$-axis & Y-axis & Z-axis \\
\hline Canine cusp tip & 0.01589 & 0.06524 & 0.04360 & 0.09032 & 0.01959 & 0.05108 & 0.1227 & 0.07587 & 0.05691 & 0.01383 & 0.08800 & 0.03172 \\
\hline Pre-molar cusp tip & 0.01397 & 0.06710 & 0.04412 & 0.09397 & 0.01707 & 0.01019 & 0.1305 & 0.07964 & 0.06504 & 0.01331 & 0.06006 & 0.066 \\
\hline lolar cusp tip & 0.01238 & 0.05594 & 0.04992 & 0.08420 & 0.01473 & 0.01053 & 0.1225 & 0.06189 & 0.07359 & 0.01397 & 0.05821 & 0.070 \\
\hline
\end{tabular}

when compared to the conventional HYRAX expander.

- The total displacement was observed maximum in the mid-palatal cleft area with the BBPE in comparison with the conventional HYRAX expander.

- Overall, the bone-borne palatal expander produced true skeletal expansion at the alveolar level without causing any dental tipping.

\section{Acknowledgements}

The authors thank Dr. Joseph Bensing, Scientist, and Mr. Santhosh, Senior Research Officer, Department of ARSTPS, CIPET, Chennai, Tamilnadu, India, for helping in the finite element model creation and completion of this study.

\section{Authors' contributions}

AM carried out the finite element study, contributed particular written sections and completed the master thesis. NKS contributed the concept of the study, helped in writing the discussion and few sections of the study and in the assimilation of the figures and prepared the final compilation. DV contributed in writing few sections of the study and in the preparation of the tables and verified the final compilation. All authors read and approved the final manuscript.

\section{Competing interests}

The authors declare that they have no competing interests.

\section{Consent for publication}

Written informed consent for the publication was obtained from the participants.

\section{Ethics approval and consent to participate}

This study obtained ethical approval from Meenakshi Ammal Dental College Institutional Review Board (protocol number MADC/IRB/2014/007I).

\section{Author details}

'Department of Orthodontics, Indira Gandhi Institute of Dental Sciences, SBV University, Puducherry 605402, India. ${ }^{2}$ Department of Orthodontics and Dentofacial Orthopedics, Meenakshi Ammal Dental College \& Hospital, Meenakshi University (MAHER), Alapakkam Main Road, Maduravoyal, Chennai, Tamilnadu 600095, India.

Received: 26 August 2016 Accepted: 28 September 2016 Published online: 21 November 2016

\section{References}

1. Samuel Berkowitz. Cleft lip and palate-diagnosis and management. 2nd Edition. Berlin: Springer-Verlag; 2006.

2. Rygh $P$, Tindlund R. Orthopedic expansion and protraction of the maxilla in cleft palate patients—a new treatment rationale. Cleft Palate J. 1982;19:104-12.

3. Tindlund RS, Rygh P, Boe OE. Intercanine widening and sagittal effect of maxillary transverse expansion in patients with cleft lip and palate during the deciduous and mixed dentitions. Cleft Palate Craniofac J. 1993;30:195-207.

4. Abdoney. Use of the Arndt nickel titanium palatal expander in cleft palate cases. J Clin Orthod. 1995;29:496-9.

5. Caniklioglu MN. Use of a nickel titanium palatal expander in cleft-plate cases. J Clin Orthod. 2004;38:374-7.

6. Isaacson RJ, Murphy TD. Some effects of rapid maxillary expansion in cleft lip and palate patients. Angle Orthod. 1964;34:143-54.
7. Capelozza Filho L, De Almeida AM, Ursi WJS. Rapid maxillary expansion in cleft lip and palate patients. J Clin Orthod. 1994;28:34-9.

8. Biederman W. A hygienic appliance for rapid expansion. J Clin Orthod. 1968; 2:67-70.

9. Fink FS. Early orthodontic treatment in the cleft palate patient. J Clin Orthod. 1971;5:226-7.

10. Levrini L, Vittorio Filippi MD. A fan-shaped maxillary expander. J Clin Orthod. 1999;33:642-3

11. Bishara SE, Staley RN. Maxillary expansion: clinical implications. Am Orthod Dentofacial Orthop. 1987;91:3-14.

12. Proffit WR, Henny W Fields Jr. Contemporary orthodontics. Third. Mosby, Inc. 2000

13. Gerlach KL, Zahl C. Transversal palatal expansion using a palatal distractor. J Orofac Orthop. 2003;64:443-9.

14. Harzer W, Schneider M, Gedrange T. Rapid maxillary expansion with palatal anchorage of the hyrax expansion screw-pilot study with case presentation. J Orofac Orthop. 2004:65:419-24.

15. Harzer W, Schneider M, Gedrange T, Tausche E. Direct bone placement of the hyrax fixation screw for surgically assisted rapid palatal expansion. J Oral Maxillofac Surg. 2006;64:1313-7.

16. Tausche E, Hansen L, Hietschold V, Lagravere MO, Harzer W. Three-dimensional evaluation of surgically assisted implant bone-borne rapid maxillary expansion: a pilot study. Am J Orthod Dentofacial Orthop. 2007;131(Suppl):S92-9.

17. Lee KJ, Park Y-C, Park J-Y, Hwang W-S. Miniscrew-assisted nonsurgical palatal expansion before orthognathic surgery for a patient with severe mandibular prognathism. Am J Orthod Dentofacial Orthop. 2010;137:830-9.

18. Deeb W, Hanson L, Hotan T, Hietschold V, Harzer W, Tausche E. Changes in nasal volume after surgically assisted bone-borne rapid maxillary expansion. Am J Orthod Dentofacial Orthop. 2010;137:782-9.

19. Lagravere MO, Carey J, Heo G, Toogood RW, Major PW. Transverse, vertical, and anteroposterior changes from bone-anchored maxillary expansion vs traditional rapid maxillary expansion: a randomized clinical trial. Am J Orthod Dentofacial Orthop. 2010;137:304.e1-12.

20. Tanne K, Sakuda M, Burstone CJ. Three-dimensional finite element analysis for stress in the periodontal tissue by orthodontic forces. Am J Orthod Dentofacial Orthop. 1987;92:499-505.

21. Tanne K, Hiraga J, Kakiuchi K, Yamagata Y, Sakuda M. Biomechanica effect of anteriorly directed extraoral forces on the craniofacial complex: a study using the finite element method. Am J Orthod Dentofacial Orthop. 1989;95:200-7.

22. Iseri H, Tekkaya AE, Oztan O, Bilgic S. Biomechanical effect of rapid maxillary expansion on the craniofacial skeleton, studied by the finite element method. Eur J Orthod. 1998:20:347-56.

23. Gautam P, Valiathan A, Adhikari R. Stress and displacement patterns in the 375 craniofacial skeleton with rapid maxillary expansion: a finite element 376 method study. Am J Orthod Dentofacial Orthop. 2007;132:5.e1-5.e11.

24. Holberg C, Holberg N, Schwenzer K, Wichelhaus A, Rudzki- Janson I. 378 Q13 Biomechanical analysis of maxillary expansion in CLP patients. Angle 379 Orthod. 2007;77:280-7.

25. Pan X, Qian Y, Yu J, Wang D, Tang Y, Shen G. Biomechanical effects of rapid 381 palatal expansion on the craniofacial skeleton with cleft palate: a three 382 dimensional finite element analysis. Cleft Palate Craniofac J. 2007:44:149-54

26. Jafari A, Shetty KS, Kumar M. Study of stress distribution and displacement of 370 various craniofacial structures following application of transverse orthopedic 371 forces - a three-dimensional FEM study. Angle Orthod. 2003;73:12-20

27. Holberg C, Rudzki-Janson I. Stresses at the cranial base induced by rapid 373 maxillary expansion. Angle Orthod. 2006;76:543-50. 
28. Vyas RM, Jarrahy R, Sisodia M, Jourabchi N, Wasson KL, Bradley JP. Boneborne palatal distraction to correct the constricted cleft maxilla. J Craniofac Surg. 2009;20(3):733-6.

29. Lee HK, Bayome M, Ahn CS, Kim SH, Kim KB, Mo SS, Kook YA. Stress distribution and displacement by different bone-borne palatal expanders with micro-implants: a three-dimensional finite-element analysis. European Journal of Orthodontics Advance. 2014;36:531-40.

30. Holberg C, Steinhauser S, Rudzki I. Surgically assisted rapid maxillary expansion: mid facial and cranial stress distribution. Am J Orthod Dentofacial Orthop. 2007;132:776-82.

31. Lee JS, Park YC, Kim JK. Applications of Orthodontic Mini-Implants. llinois: Quintessence Publishing Co, Inc; 2007.

32. Suzuki A, Masuda T, Takahashi I, Deguchi T, Suzuki O, Takano-Yamamoto T. Changes in stress distribution of orthodontic miniscrews and surrounding bone evaluated by 3-dimensional finite element analysis. Am J Orthod Dentofacial Orthop. 2011;140:e273-80.

33. Singh S, Mogra S, Shetty VS, Shetty S, Philip P. Three-dimensional finite element analysis of strength, stability, and stress distribution in orthodontic anchorage: a conical, self-drilling mini-screw implant system. Am J Orthod Dentofacial Orthop. 2012;141:327-36.

34. Middleton J, Jones $\mathrm{M}$, Wilson $\mathrm{A}$. The role of the periodontal ligament in bone modelling: the initial development of a time-dependent finite element model. Am J Orthod Dentofacial Orthop. 1996;109:155-62.

35. Toms SR, Eberhardt AW. A nonlinear finite element analysis of the periodontal ligament under orthodontic tooth loading. Am J Orthod Dentofacial Orthop. 2003:123:657-65.

36. Gautam P, Valiathan A, Adhikari R. Maxillary protraction with and without maxillary expansion: a finite element analysis of sutural stresses. Am J Orthod Dentofacial Orthop. 2009;136:361-6.

37. Gautam P, Zhao L, Patel P. Biomechanical response of the maxillofacial skeleton to transpalatal orthopedic force in a unilateral palatal cleft. Angle Orthod. 2011;81:503-9.

38. Ufuk Toygar Memikoglu T, Iseri H. Effect of bonded rapid maxillary appliance during orthodontic treatment. Angle Orthod. 1999;69(3):251-6.

39. Chung C-H, Font B, de Mallorca P. Skeletal and dental changes in the sagittal, vertical, and transverse dimensions after rapid palatal expansion. Am J Orthod Dentofacial Orthop. 2004:3:345-51.

40. Melsen B, Melsen F. The postnatal development of the palatomaxillary region studied on human autopsy material. Am J Orthod. 1982;82:329-42.

41. Ngan P, Wilmes B, Drescher D, Martin C. Comparison of two maxillary protraction protocols: tooth-borne versus bone-anchored protraction facemask treatment. Prog Orthod. 2015;16:26.1-11.

42. Lin L, Ahn H-W, Kim S-J, Moon S-C, Kim S-H, Nelson G. Tooth-borne vs bone-borne rapid maxillary expanders in late adolescence. Angle Orthod. 2015;85:253-62.

\section{Submit your manuscript to a SpringerOpen ${ }^{\circ}$ journal and benefit from:}

- Convenient online submission

- Rigorous peer review

- Immediate publication on acceptance

- Open access: articles freely available online

- High visibility within the field

- Retaining the copyright to your article

Submit your next manuscript at $\boldsymbol{s p r i n g e r o p e n . c o m ~}$ 